\title{
Pseudogout of the Transverse Atlantal Ligament: An Unusual Cause of Cervical Myelopathy
}

\author{
Donald E.G. Griesdale, Jr., Mike Boyd, Ramesh L. Sahjpaul
}

\begin{abstract}
Background: Calcium pyrophosphate dihydrate deposition in the cervical spine is infrequently symptomatic. This is especially true at the craniocervical junction and upper cervical spine. Case Report: A 70-year-old previously healthy woman presented with a progressive cervical myelopathy of four months duration. Results: Examination revealed sensorimotor findings consistent with an upper cervical myelopathy. Radiological studies (plain radiographs, computed tomography, and magnetic resonance imaging) revealed C1-2 instability, and a well-defined extradural $3 \mathrm{~cm} \times 1 \mathrm{~cm}$ retroodontoid mass causing spinal cord compression. Transoral resection of the mass was performed followed by posterior C1-2 stabilization. Histological examination of the mass confirmed calcium pyrophosphate dihydrate deposition. Follow-up examination showed marked clinical and radiological improvement. Conclusion: Although uncommon, calcium pyrophosphate dihydrate deposition disease should be considered in the differential diagnosis of extradural mass lesions in the region of the odontoid.
\end{abstract}

RÉSUMÉ: Pseudo-goutte du ligament transverse de l'atlas: une cause rare de myélopathie cervicale. Introduction: Il est rare que des dépôts de pyrophosphate dihydrate de calcium provoquent des symptômes, particulièrement quand ils sont situés à la jonction crânio-cervicale et à la région supérieure du rachis cervical. Observation: Une femme de 70 ans, sans antécédents médicaux, a consulté pour une myélopathie cervicale évoluant depuis 4 mois. Résultats: L'examen physique a montré des anomalies sensitivo-motrices compatibles avec une myélopathie cervicale haute. L'imagerie (radiographie simple, tomodensitométrie et résonance magnétique) ont montré une instabilité $\mathrm{C} 1-\mathrm{C} 2$ et une masse épidurale, rétro-odontoïde, bien définie de $3 \mathrm{~cm}$ par $1 \mathrm{~cm}$ comprimant la moelle épinière. La patiente a subi une résection transorale de la masse avec stabilisation postérieure $\mathrm{C} 1-\mathrm{C} 2$. L'examen histologique de la masse a confirmé qu'il s'agissait d'un dépôt de pyrophosphate dihydrate de calcium. L'état clinique de la patiente, ainsi que l'imagerie, se sont améliorés de façon importante. Conclusion: Bien que rare, le dépôt de pyrophosphate dihydrate de calcium doit être inclus dans le diagnostic différentiel des masses épidurales situées dans la région de l'apophyse odontoïde.

Can. J. Neurol. Sci. 2004; 31: 273-275

Calcium pyrophosphate dihydrate (CPPD) deposition disease is an inflammatory arthropathy characterized by the deposition of weakly positively birefringent crystals in articular and periarticular structures. It has also been referred to as pseudogout (owing to its clinical similarity to gout) and articular chondrocalcinosis. The CPPD crystals are deposited exclusively in joints and bursae, with occasional extension beyond the anatomical confines of the joint. The cervical spine is uncommonly affected, and symptomatic cervical spine involvement is rarer still. There have been only 12 reported cases of symptomatic CPPD deposition disease involving the $\mathrm{C} 1-2$ articulation. $^{1-6}$

We describe a case of an elderly woman who developed a progressive cervical myelopathy from $\mathrm{C} 1-2$ instability associated with CPPD deposition disease involving the transverse atlantal ligament.

\section{CASE REPORT}

A 70-year-old right-handed woman began noticing numbness beginning in her left big toe and gradually ascending to involve both lower extremities, left greater than right. Two months later, she developed left hand numbness and weakness. She presented shortly thereafter with complaints of a constant numbness in both legs and the left side of her trunk and left hand, weakness of her left hand, and a

From the Division of Neurosurgery, Combined Neurosurgical and Orthopedic Spine Program, Vancouver General Hospital, University of British Columbia, Vancouver BC Canada.

ReCeived April 17, 2003. ACCePted infinAlform November 25, 2003 Reprint requests to: Ramesh L. Sahjpaul, 3878 W 18th Ave, Vancouver BC V6S 1B5 Canada. 

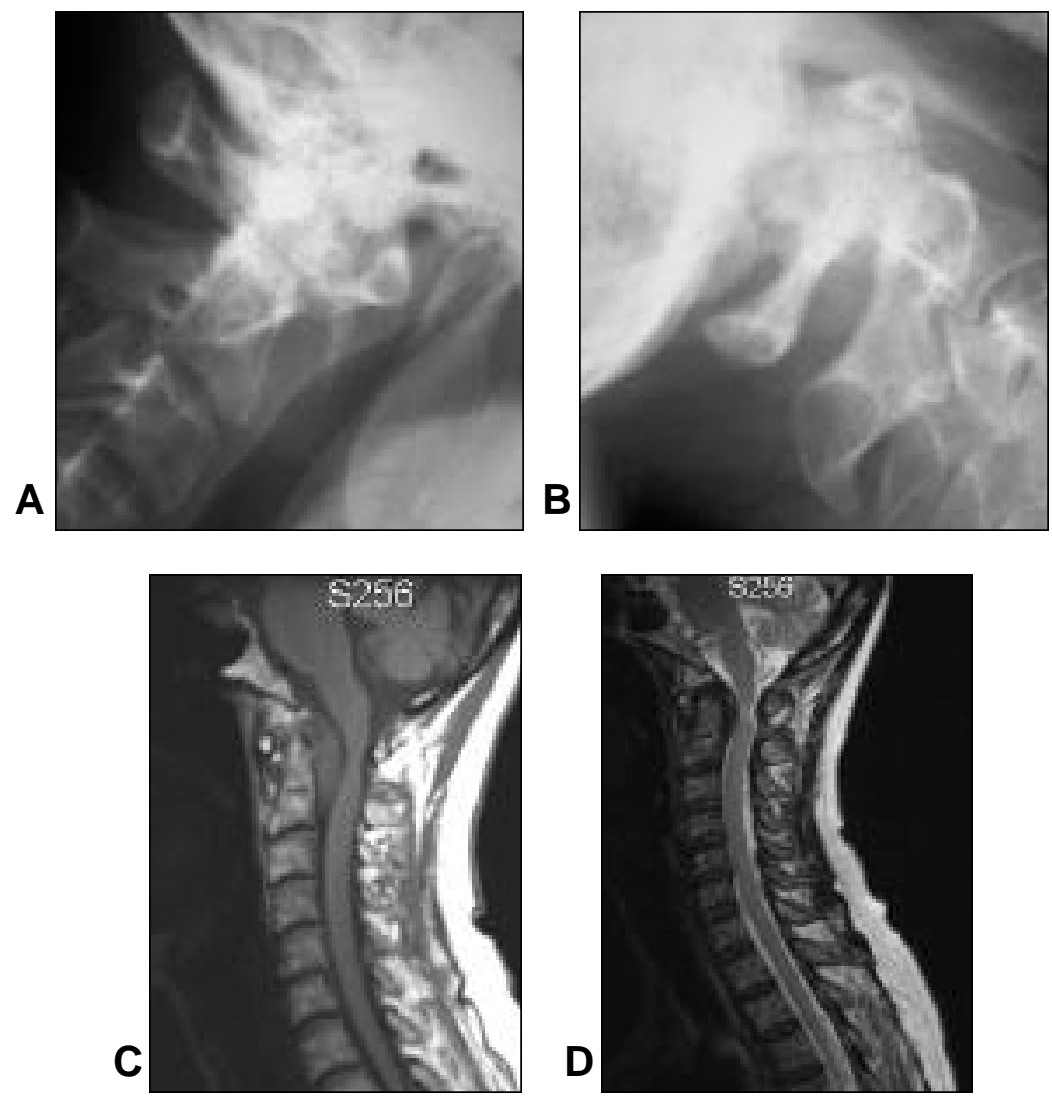

Figure 1: Preoperative radiographs demonstrating instability with cervical spine flexion $(\boldsymbol{A})$ and extension $(\boldsymbol{B})$. Magnetic resonance imaging demonstrating a retroodontoid mass iso-intense on $T 1(\boldsymbol{C})$ and mixed intensity on $T 2(\boldsymbol{D})$ sequences.

buzzing sensation down the left side of her body with neck extension. Her right upper extremity was unaffected and she denied bowel or bladder difficulties. Past medical history was remarkable for tuberculous peritonitis treated as a child, and bilateral carpal tunnel release. There was no history of rheumatoid arthritis.

Neurological examination revealed increased tone in both lower extremities (left greater than right), brisk reflexes throughout, flexor plantar responses, abnormal spread of brachioradialis reflexes bilaterally and bilateral crossed adductor responses. Motor testing revealed mild weakness in left deltoid and hip flexors. She had a mildly spastic gait.

Plain cervical spine flexion extension x-rays demonstrated C1-2 instability with an increase in the atlanto-dental interval from $4 \mathrm{~mm}$ in the neutral position to $9 \mathrm{~mm}$ in flexion (Figure 1A and 1B). Magnetic resonance (MR) imaging of the cervical spine demonstrated a welldefined $3 \mathrm{~cm} \times 1 \mathrm{~cm}$ retro-odontoid, extradural mass causing spinal cord compression with increased $\mathrm{T} 2$ signal in the spinal cord. The lesion was hypointense on $\mathrm{T} 1$ and hyperintense on $\mathrm{T} 2$-weighted images, and enhanced minimally with gadolinium (Figures 1C and 1D). Computerized tomography demonstrated only minimal calcification with no adjacent bony changes.

\section{Surgery}

A transoral resection of the odontoid and extradural retro-odontoid mass was performed. The mass was avascular and had a yellowish colour and fibrous texture. It was moderately adherent to the dura. After ventral decompression, a posterior C1-2 stabilization was performed with a right-sided transarticular screw and interlaminar fusion with autograft.

\section{Pathology}

Histological examination of the mass demonstrated CPPD crystals deposited in a fibrocartilaginous matrix (Figure 2). Synovium within the specimen showed focal reactive changes with synovial proliferation and accumulation of foamy macrophages.

\section{Postoperative course}

The patient's immediate postoperative course was uncomplicated. Postoperative MR scan demonstrated complete resection of the mass. Six months following surgery she demonstrated a nearly complete resolution of her deficits and radiological stability at C1-2.

\section{DiscuSSION}

Although CPPD deposition disease frequently manifests as a primary arthropathy unassociated with any other disorder, it can be associated with any of several endocrine or metabolic disorders, including hemochromatosis, diabetes mellitus, hyperparathyroidism, hypothyroidism, Wilson's disease, hypophosphatasia, gout and rheumatoid arthritis. ${ }^{2}$ In addition, 


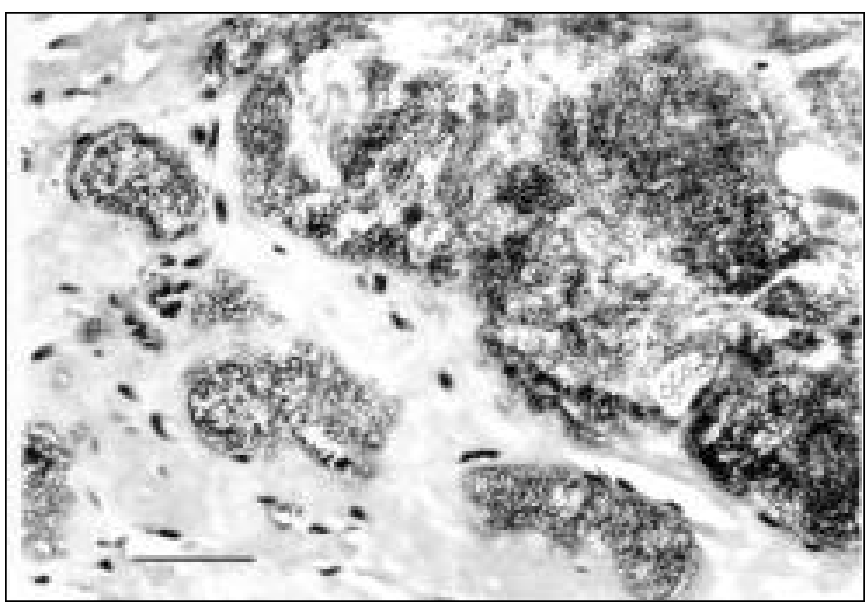

Figure 2: Hematoxylin and eosin examination shows masses of rod shaped CPPD crystals deposited in the fibrocartilaginous matrix. (bar $=.25$ micrometers.)

several forms of hereditary CPPD deposition disease have been reported. ${ }^{7}$ Importantly, many patients with either radiological or microscopic evidence of CPPD deposition disease are asymptomatic. $^{2}$

Calcium pyrophosphate dihydrate deposition disease involving the spine has been increasingly reported in the literature. A study by Markiewitz et $\mathrm{al}^{8}$ demonstrated axial involvement in $33 \%$ of patients with CPPD deposition disease, with $87 \%$ of these being in the lumbar spine. Despite this high incidence of lumbar spine involvement, symptomatic lumbar disease is very rare with only a few reported cases. ${ }^{9}$ In contrast, symptomatic cervical spine involvement appears to be more common and has been reported in 24 cases. $^{2}$ With respect to the upper cervical spine, studies have reported radiological evidence of transverse atlantal ligament involvement in $44 \%$ to $66 \%{ }^{10,11}$ of patients with known CPPD deposition disease, but there have been only 12 reported cases of symptomatic disease involving the $\mathrm{C} 1-2$ articulation. ${ }^{1-6}$ It is interesting to note that, as in our case, the majority of reported cases occurred in older women. ${ }^{2,12}$

Signs and symptoms of CPPD deposition disease involving the cervical spine include neck pain, stiffness, and myelopathy. ${ }^{1}$ Computed tomography typically shows speckled calcification within the transverse atlantal ligament or retro-odontoid mass (if present). These lesions are typically isointense to neural tissue on T1-weighted MR images and of mixed intensity on T2-weighted images, and demonstrate peripheral enhancement with gadolinium. ${ }^{1}$ Symptomatic patients with retro-odontoid CPPD deposition require surgical decompression, which is almost always performed transorally. The lesion is typically a firm, yellowish, avascular mass. ${ }^{6}$ Most reported cases also required posterior stabilization. One of seven patients reported by Zunkeler et al, ${ }^{1}$ and both patients reported by Assaker et al, ${ }^{6}$ were not stabilized posteriorly because follow-up imaging failed to demonstrate instability. Our patient had evidence of instability preoperatively and hence was stabilized posteriorly with a C1-2 transarticular screw and interlaminar fixation. We did not feel it was necessary to incorporate the occiput into the posterior fusion construct as others have done. ${ }^{1}$

In addition to CPPD deposition disease, the differential diagnosis of a retro-odontoid calcified mass includes rheumatoid pannus, Paget's disease, and acromegaly. ${ }^{6}$ If CPPD deposition disease is entertained preoperatively, the pathologist should be alerted so as to be able to use a polarizing light for birefringence at the time of initial frozen section and during subsequent tissue diagnosis. As in our case, most patients experience rapid and substantial improvement in signs and symptoms after surgical decompression. ${ }^{1,6}$ The natural history of CPPD deposition disease is poorly understood. In approximately $10 \%$ of patients, the disease becomes a chronic progressive polyarticular arthropathy resembling rheumatoid arthritis and requiring long term follow-up. ${ }^{7}$

\section{ACKNOWLEDGEMENTS}

We thank Dr. Katerina Dorovini-Zis for providing the pathology photographs.

\section{REFERENCES}

1. Zunkeler B, Schelper R, Menezes AH. Periodontoid calcium pyrophosphate dihydrate deposition disease: "pseudogout" mass lesions of the craniocervical junction. J Neurosurg 1996;85:803809.

2. Fye KH, Weistein PR, Donald F. Compressive cervical myelopathy due to calcium pyrophosphate dihydrate deposition disease. Arch Intern Med 1999;159:189-193.

3. Ciricillo SF, Weistein PR. Foramen magnum syndrome from pseudogout of the atlanto-occipital ligament: case report. J Neurosurg 1989;71:141-143.

4. Ishida T, Dorfmann HD, Bullough PG. Tophaceous pseudogout (tumoral calcium pyrophosphate dihydrate crystal deposition disease). Hum Pathol 1995;26:587-593.

5. Wells CR, Morgello S, Dicarlo E. Cervical myelopathy due to calcium pyrophosphate dihydrate deposition disease. J Neurol Neurosurg Psychiatry 1991;54:658-659.

6. Assaker R, Louis E, Boutry N, et al. Foramen magnum syndrome secondary to calcium pyrophosphate crystal deposition in the transverse ligament of the atlas. Spine 2001;26:1396-1400.

7. Howell DS. Diseases due to the deposition of calcium pyrophosphate and hydroxyapatite. In: Kelley WN, Harris ED, Ruddy S, Sledge CB, (Eds). Textbook of Rheumatology. Philadelphia, Pa: WB Saunders Co; 1981.

8. Markiewitz A, Boumphrey F, Bauer T, et al. Calcium pyrophosphate dihydrate crystal deposition disease as a cause of lumbar canal stenosis. Spine 1996;21:506-511.

9. Takaaki F, Nabeshima Y, Shinji Y, et al. Pseudogout attack of the lumbar facet joint: a case report. Spine 2002;27:396-398.

10. Dirheimer Y, Bensimon C, Christmann D, et al. Syndesmo-odontoid joint and calcium pyrophosphate dihydrate deposition disease (CPPD). Neuroradiology 1983;25:319-321.

11. Constantin A, Marin F, Fedele M, et al. Calcification of the transverse ligament of the atlas in chondrocalcinosis: computed tomography study. Ann Rheum Dis 1996;55:137-139.

12. Muthukumar N, Karuppaswamy U. Tumoral calcium pyrophosphate dihydrate deposition disease of the ligamentum flavum. Neurosurgery 2003;53:103-108. 